\title{
JULY 1987
}

\section{ENVIRONMENTAL ASSESSMENT}

CHEMICAL RELEASE EXPERIMENT 


\section{FINDING OF NO SIGNIFICANT IMPACT (FONSI) \\ CHEMICAL RELEASE EXPERIMENT \\ U.S. AIR FORCE SPACE DIVISION}

\subsection{INTRODUCTION}

1. The U.S Air Force proposes to conduct an experiment to identify the potential environmental consequences of an inadvertent release of hydrazine rocket propellant in space, during orbital or suborbital operations. The experiment will be sponsored by the Space Defense Initiative Organization. The experiment will be managed by the U.S Air Force Space Technology Center.

2. The experiment will be conducted in the thermosphere of outer space, at an earth of about $300 \mathrm{~km}$.

3. The experiment will involve the ejection of three Get Away Special (GAS) satellites (one during the first and two during the second Shuttle flight), each containing about 100 pounds of specified hydrazine fuel, plus the required circuitry for tracking and ordinance activation.

4. The satellites will be ejected from a Space Shuttle which will be launched from Kennedy Space Center.

2.0 IMPACTS

\subsection{IMPACTS OF THE PROPOSED EXPERIMENT}

\subsubsection{HYDRAZINE TRANSPORT TO THE TROPOSHERE}

1. It is anticipated the virtually none of hydrazine would reach the troposphere (the atomosphere extending from the surface of the earth outward to about 10 to 15 kilometers).

2. Small amounts, if any, of hydrazine reach ing the troposphere would be duiluted by more than $10^{18}$ pounds of air by the time any reached the ground on the order of years after its release. 


\subsubsection{TRANSPORT OF REACTION PRODUCT TO THE TROPOSHERE}

1. The effects of hydrazine reaction product s would not be significant, regradless of whether they were transported to the troposphere, primarily because most of products are standard atmospheric components.

2. The reaction of hydrazine with ozone in the upper atmosphere can potentially produce nitrosamines. However, these compounds would be degraded by reaction with $\mathrm{OH}$ radicals and daytime photolysis. Therefore, any nitrosamine produced by ozone reactions with hydrazine would be consumed before reaching the troposphere.

\subsubsection{LOCALIZED INCREASE IN ULTRAVIOLET RADIATION}

1. Because of the unmeasurably small quantity of ozone which could be depleted as a result of the proposed experiment, the quantitative increase in ultraviolet radiation would be insignificant

2. There would be no significant effect to either human populations of the natural marine environments (specifically, phytoplankton).

\subsection{IMPACT OF POTENTIAL ACCIDENTS}

\subsubsection{ON GROUND ACCIDENT}

1. Potential on-ground accidents would likely be associated with Space Shuttle launch and landing. The addition of the hydrazine canisters would not be significant.

2. An accident spill during transport or onsite handling of the canisters would produce only localized, insignificant effects and would be handled in in accordance with existing administrative procedures currently followed by the Air Force and NASA.

3. An accidental explosion during transport and handling to the launch site could also produce localized effects. These, too, would be handled in accordance with existing administrative procedures. 


\subsubsection{LIFTOFF ACCIDENTS IN SPACE}

1. The principal potential accident during liftoff is an explosion induced by manlfunction in the Shuttle launch vehicle, resulting of the canisters and ignition of the hydrazine. The subsequent exhaust product have been shown to have no significant environment impact.

2. Should the hydrazine fuel be released into the ocean from both canisters simultaneously, the concentration is estimated to be $40 \mathrm{ppm}$ at a distance of 0.1 mile, well below the toxicity level of $146 \mathrm{ppm}$. This would produce only a temporary and highly localized effect. The overall impact would be insignificant.

\subsubsection{ACCIDENTS IN SPACE}

1. There would be no significant impact from an explosion in the upper atmosphere, prior to either the release of the canisters or the command for detonation.

2. In the event of an error in orbital placement, the GAS container would either fall to earth and be burned in the atmosphere or leave the gravitational system of the earth. In either event, there would be no significant impact.

3. A loss or ordinance control resulting in either an inability to detonate or incorrect detonation would not create significant environment impact.

\subsection{MITIGATIONS}

1. The canister will be designed to the requirements of the GAS container dimensions and weight limitations.

2. The Air Force has developed appropriate safety (administrative) procedures for the routine handling, transport, and utilization of hydrazine fuels which are utilized for numerous other operations.

3. Safety and other operational requirements of the Shuttle will be fulfilled by the contractor selected to design and construct the hardware and provide integration services.

4. Provisions will be made for unloading the canisters in the event of an extended launch delay or 
other such circumstances.

\subsection{ALTERNATIVE}

\subsection{LABORATORY TEST ALTERNATIVE}

1. This alternative would require the duplication of both upper atmospheric conditions and the mechanism for diffusion of hydrazine and reaction products in the atmospheric. It would be virtually impossible to simulate in the laboratory the phenomena which will be tested by this release.

2. This alternative, therefore, is not feasible.

\subsection{FINDINGS}

1. In view of the above, a finding of no significant impact is made.

2. An Environmental Assesment for the proposed Hydrazine Release Experiment July 22,1987 , is on file at:

HQ Space Division

Post Office Box 92960

Worldway Postal Center

Los Angeles, California 90009

ATTENTION: Mr John Edwards, SD/DEV

Raphael O. Roig

Date

Chairman Space Division

Environmental Protection Committee 


\section{CONTENT}

LIST OF FIGURES

PAGE NO.

1.0 PROPOSED ACTION AND ALTERNATIVES 1-1

1.1. Proposed Action 1-1

1.1.1 Summary 1-1

1.1.2 Conduct of the Experiment 1-4

1.1.3 Potential Accidents 1-5

1.1.3.1 On-Ground Accidents $1-5$

1.1.3.2 Accidents in Space 1-8

1.2 Relationship of Proposed Action to Land Use Plans, Policies and Control s for the Affected Area 1-9

1.2.1 Space Shuttle Activities 1-9

1.2.2 Activities in Space 1-9

1.3 Alternatives to the Proposed Project 1-9

1.31 Laboratory Tests 1-9

1.3.2 No-Action Alternative $1-9$

2.0 EXISTING ENVIRONMENT 2-1

2.1 Introduction 2-1

2.2 Earth Environment 2-1

2.21 Kennedy Space Center Launch Site 2-1

2.2.2 Earth Atmosphere 2-1

2.3 Space Environment 2-1

2.3.1 Thermosphere 2-1

2.3.2 Mesosphere 2-3

2.3.3 Stratosphere 2-3

3.0 ENVIRONMENTAL IMPACTS OF THE PROPOSED ACTION

3.1 Introduction 3-1

3.2 Air Quality 3-1

3.2.1 Consequences of Experiment 3-1.

3.2.1.1 Expected Results 3-1

3.2.1.2 Hydrazine Transport 3-2

3.2.1.3 Hydrazine Reaction Products 3-2

3.2.1.4 Ultraviolet Radiation 3-4 
(Continued)

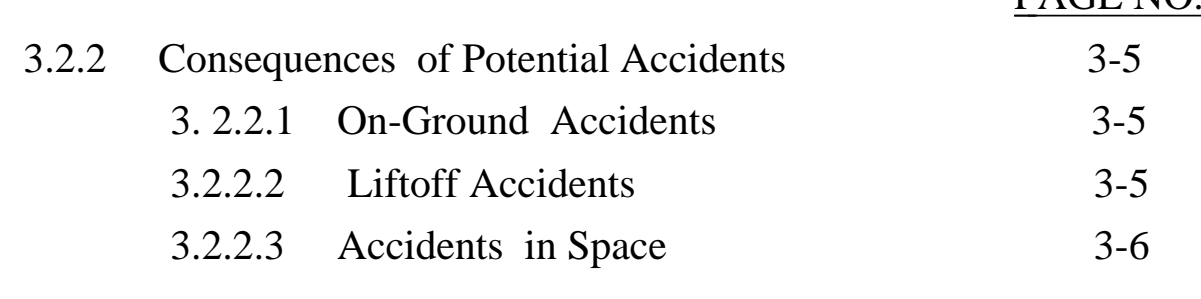

3.3 Human Populations 3-7

3.3.1 Ultraviolet Radiation 3-7

3.3.2 On-Ground Accidents 3-8

3.4 Surface Water Effects 3-8

3.5 Natural Ecology 3-9

3.6 Noise Effects 3-10

3.7 Summary Of Impacts 3-10

4.0 ALTERNATIVES TO THE PROPOSED PROJECT 4-1

4.1 Laboratory Tests Alternative 4-1

4.2 No-Action Alternative 4-1

4.3 Summary 4-2

5.0 UNAVOIDABLE ADVERSE EFFECTS AND MITIGATION

MEASURES $\quad 5-1$

6.0 RELATIONSHIPS BETWEEN LOCAL, SHORT-TERMS USE OF

THE ENVIRONMENT AND THE MAINTENANCE AND

ENHANCEMENT OF LONG-TERM PRODUCTIVITY 6-1

7.0 IRREVERSIBLE AND IRRETRIEVABLE COMMITMENTS OF

RESOURCES THAT WOULD BE INVOLVED IN THE

PROPOSED ACTION, SHOULD IT BE IMPLEMENTED 7-1

8.0 CONSIDERATIONS THAT OFFSET THE ADVERSE

ENVIRONMENTAL EFFECTS $\quad 8.1$

9.0 PERSONS AND ORGANIZATIONS CONTACTED 9-1

10.0 REFERENCES 10-1

APPENDIX A: Diffusion of Hydrazine Fuels in the Upper Atmosphere

APPENDIX B: Hydrazine Concentration in Ocean Following Potential Liftoff Explosion 


\section{LIST OF FIGURES}

FIGURE NO

1.1

1.2

1.3

1.4

2.1

2.2 $\underline{\text { TITLE }}$

Earth Atmosphere in Layers

$1-2$

Proposed Hydrazine Release

$1-3$

GAS Satellite Installation and Planned Ejection

Mechanism

$1-6$

Satellite Orbit, Aircraft Ground Track ,and Release Area

$1-7$

Vertical Distribution of Temperature in Atmospheric

Regions

$2-2$

Atmospheric Pressure and Temperature with Altitude 


\subsection{PROPOSED ACTION AND ALTERNATIVES}

\subsection{PROPOSED ACTION}

\subsubsection{SUMMARY}

1. The U.S Air Force proposes to conduct an experiment to identify the potential environmental consequences of an in inadvertent release of hydrazine rocket propellant in space. The experiment will be sponsored by the Space Defense Initiative Organization. The experiment will be managed by the Air Force Technology Center .

2. The purpose of the proposed experiment is to gather data on the results of an inadvertent release of hydrazine rocket propellant during orbital or suborbital operations. The data obtained will depict the mechanism involved in the subsequent interaction of the uncontained fuels with the ambient atmosphere, particularly: (1) the processes involved in the formation of cloud of particles and vapor, (2.) the rates of the associated chemical reactions, and (3) the resultant products

3. After being launched from Kennedy Space Center, Florida, the experiment will be conducted in outer space, in the region known as the thermosphere, at an earth altitude of about $300 \mathrm{~km}$. The various atmospheric designations are shown on Figure 1.1, Earth Atmosphere in Layers.

4. The experiment will involve the ejection of three Get Away Special (GAS) satellites (one during the first and two during the second Shuttle flight), each containing about 100 pounds of hydrazine fuel. The hydrazine will be release $d$ into the upper atmosphere at an altitude of approximately $300 \mathrm{~km}$, at a specified time and location, as shown on Figure 1.2, Proposed Hydrazine Release.

5. In order for the proposed experiment to be conducted, the occurrence of at least one space launch is necessary, with its attendant risks and impacts, These potential effects were addressed in detail in the Final Environmental Impact Statements prepared for the Shuttle Launch by the National Aeronautics and Space Administration (NASA 1978) and the Department of the Air Force ( AF 1978). Therefore, the conclusion and findings presented in the Shuttle EIS are adopted as they relate to the hydrazine fuels experiment. The Shuttle EIS document are incorporated by reference and referred to collectively as the Shuttle EIS, unless one or the other is referenced individually. 


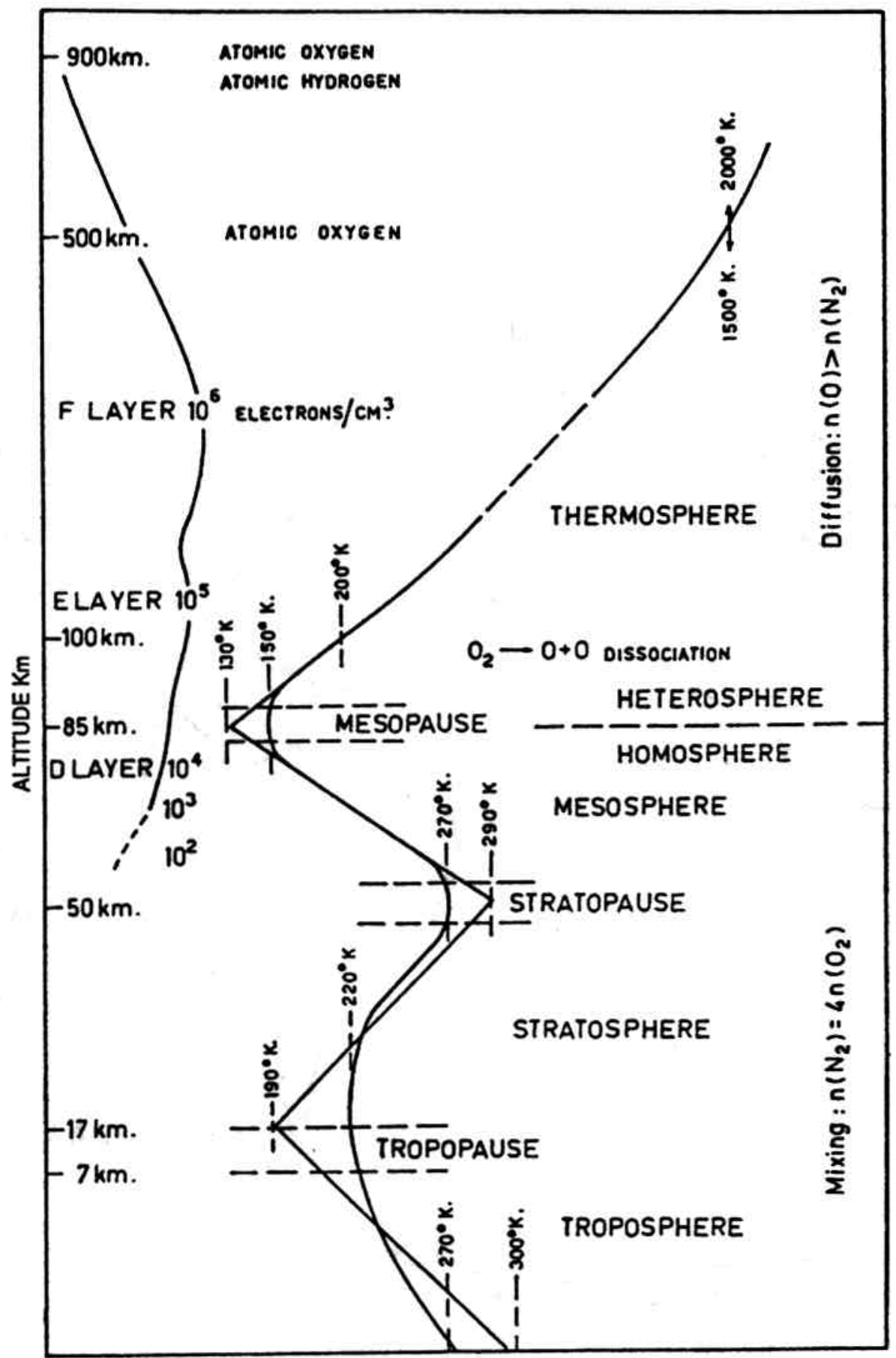

TEMPERATURE ${ }^{\circ} \mathrm{K}$

NOTE: Atmospheric Nomenclature -

The main names of the atmospheric regions, from troposphere to thermosphere, are based on a thermal classification. When the classification is given according to composition, the term homosphere means that the mean molecular mass is constant, and heterosphere means that the mean molecular mass varies. Names such as ionosphere, chemosphere, and ozonosphere are descriptive of regions where particular processes take place.

FIGURE 1.1

EARTH ATMOSPHERE IN LAYERS 


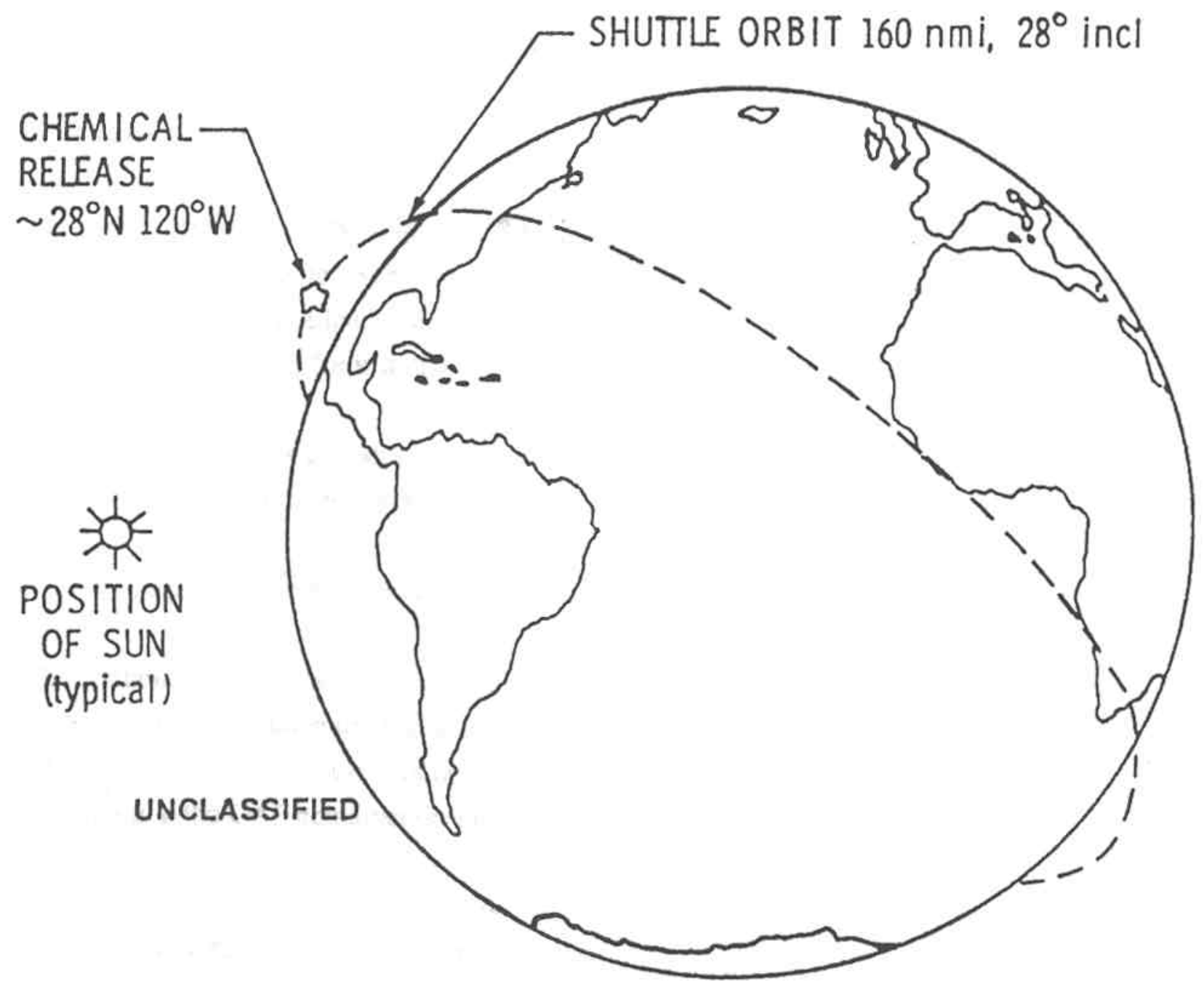

FIGURE 1.2

PROPOSED HYDRAZINE RELEASE HYDRAZINE RELEASE EXPERIMENT 


\subsubsection{CONDUCT OF THE EXPERIMENT}

1. The initial experiment will involve the ejection of one canister. Subsequently, a two-canister ejection experiment will be performed with different fuels selected after analysis of the result of this experiment.

2. The empty canisters will be shipped to Goddard Space Flight Center for installation in the GAS containers. The containers subsequently will be loaded with hydrazine at an Air Force facility at Cape Canaveral. The loaded GAS containers than will be transported to the NASA facility a Kennedy Space Center for installation in space shuttle orbiter bay.

3. Each canister will be a cylindrical container comprised of two compartments. One compartment will contain a pressure vessel with hydrazine. The second, separate compartment will contain a power supply, a beacon for ground tracking, a receiver, and other circuitry required for ordnance activation.

4. The Container pressure will be the order of one atmosphere (approximately 15 pounds per square inch). The maximum container pressure would then correspond to the vapor pressure which could result in the event of either an extended stay on the launch pad or the canister remaining in the GAS container during landing.

5. The canister and GAS container will be designed to with stand anticipated transportation accidents. In addition, NASA and Air Force operational and safety procedures will be followed for all handling and transportation of the loaded canisters.

6. The GAS satellites will be transported to altitude aboard the Shuttle, likely with an onboard crew. The satellites will be ejected from the space shuttle, then tracked by ground facilities to establish a precise ephemeris. A conceptual diagram of the GAS Satellite Installation and Planned Ejection Mechanism is shown on Figure 1.3. 
7. An orbit for the chemical release will then be selected, and sensor-bearing aircraft will be deployed to the appropriate stations for viewing the release. The aircraft will be precisely vectored with radar by controllers on the ground to the selected locations. The command for ordnance activation will be transmitted from the Western Space Missile Center, Vandenberg AFB, California.

8. The release of the hydrazine fuel will occur when each satellite had reached a point in its orbit such that it can be optimally viewed by sensors aboard the observation aircraft. This is illustrated on Figure 1.4, Satellite Orbit, Aircraft Ground Track, and Release Area.

9. Specific chemicals involved in the experiment may include: monomethyl hydrazine the fuel which is used in the Orbiter Maneuvering System (OMS) and attitude control thrusters of the orbiter, 2) aerozine-50, a1:1 mixture neat hydrazine and unsymmeterical dimethyl hydrazine (UDMH) which is used in Titan launch vehicles, 3) UDMH alone, 4) monomethy 1 hydrazine alone, and 5) possibly hydrazine.

\subsubsection{POTENTIAL ACCIDENTS}

\subsubsection{On Ground Accidents}

1. The overall potential environmental impacts of ground accidents associated with the shuttle launch and landing were addressed in the Shuttle EIS (NASA) 1978). It was concluded that impact from the release of hydrazine utilized by the shuttle would be insignificant. However, for purpose of this Environmental Assessment, there follow a brief discussion of potential accident opportunities.

2. There is the potential for an accident to occur during onsite handling and transportation. This could occur delivery of the hydrazine canisters to launch site and/or installation in the orbiter bay. Such accident could be either a spill or explosion due to canister failure or mishandling by onsite personnel or equipment.

3. There is the possibility of an accident during liftoff. The principal potential is an explosion induced by malfunction in the shuttle launch vehicle. If such an explosion occurred, the explosion force and temperature could be expected to result in failure of the hydrazine canister and ignition of the hydrazine. 

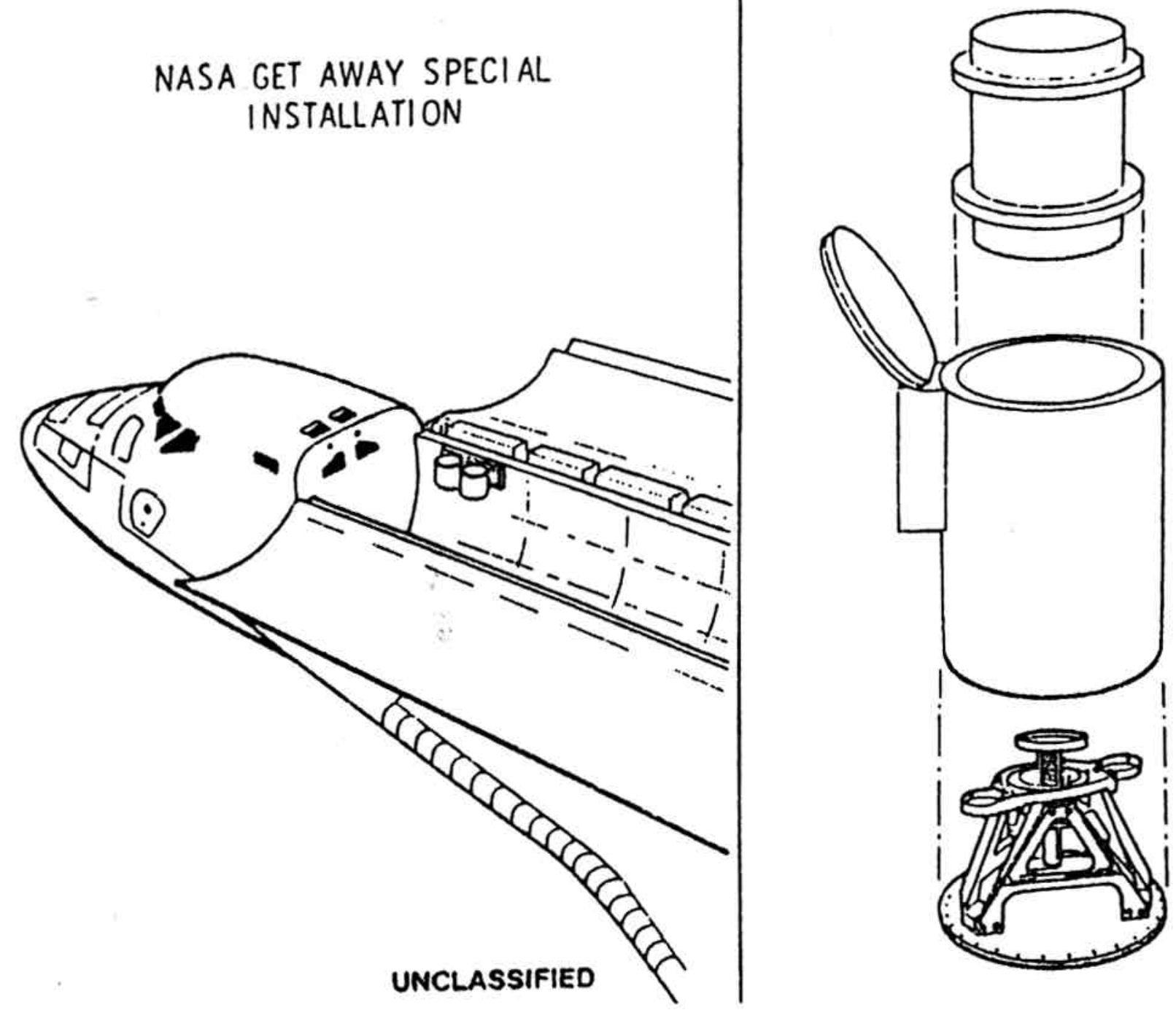

\section{CRE \\ CANISTER}

GAS

CONTAINER

\section{EJECTION}

MECHANISM

UNCLASSIFIED

FIGURE 1.3

GAS SATELLITE INSTALLATION AND PLANNED

EJECTION MECHANISM

HYDRAZINE RELEASE EXPERIMENT

ENVIRONMENTAL SOLUTIONS, INC. 


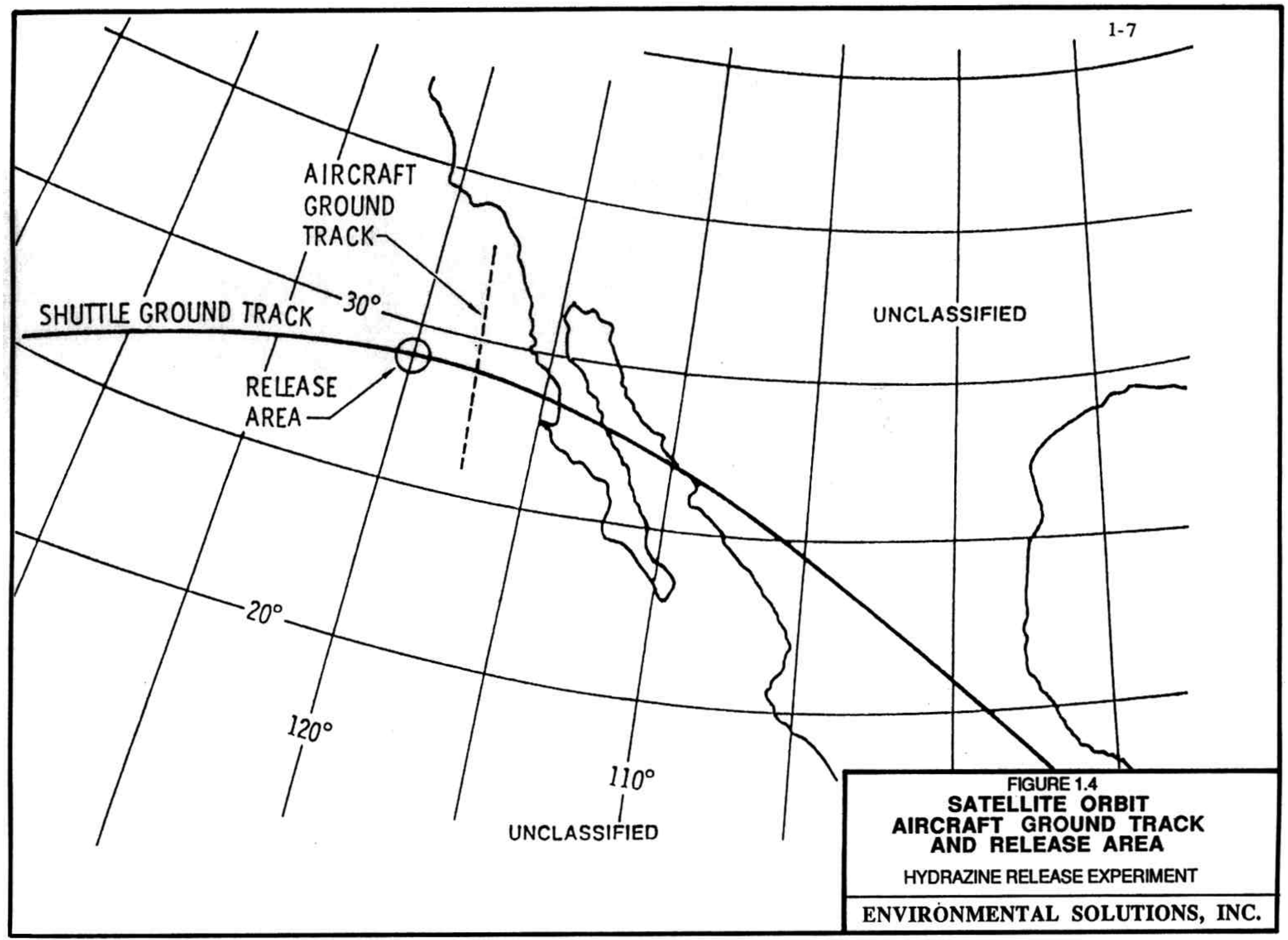


4. There is also the possibility that a canister would fail during liftoff and either leak or explode while stored in the orbiter bay.

\subsubsection{Accidents is Space}

1. Shuttle orbiting accidents are considered in the shuttle EIS. The addition of hydrazine GAS containers to the orbiter will not alter either the probability or the consequences of any such accident. Consequently, only potential accident which could involve the orbiting GAS containers are here. Each of the low probability accident considered considered follows ejection of the GAS container from the Space Shuttle.

2. An explosion could occur prior to the conduct of the experiment, due to defective container design. The effect would be to release exhaust products of hydrazine combu stion into the upper atmosphere. Another potential scenario would be the explosion of the GAS container after placement in low earth orbit, but before the command for ordnance detonation. Such explosion could be the result of an ordnance malfunction which would cause premature ignition of the hydrazine.

3. There could be an error in orbit placement. This would result in container(s ) either falling back to earth or leaving the gravitational field of the earth.

4. There could be a GAS container orbiting accident associated with the loss of ordnance control, resulting in either: (1) in ability to detonate the ordnance due to failure of some part of the communication system, or (2) detonation of the ordnance under incorrect experimental condition relative to location.

\section{$1 . .2$ RELATIONSHIP OF PROPOSED ACTION TO LAND USE PLANS, POLICIES AND CONTROLS FOR THE AFFECTED AREA}

\subsubsection{SPACE SHUTTLE ACTIVITIES}

1. The relationship of the effect of Space Shuttle activities at KSC to existing land use plans, policies, and controls was addressed in detail in the Shuttle EIS (NASA 1978). 
2. It was concluded that shuttle activities would have no adverse effect, primarily because land used to support the Space Shuttle program had previously been utilized for other space program activity. Also, air and sea restrictions would be enacted during launch, similar to those already in practice for expendable launch vehicles.

\subsubsection{ACTIVITIES IN SPACE}

1. The proposed experiment would be conducted in open, uncontrolled space, altitudes exceeding those utilized by conventional aircraft. In addition, ordnance detonation would occur over the Pacific Ocean in an open area several hundred miles west of Baja California.

2. Therefore, activities in space are not expected to affect existing policies or control for the involved area.

\subsection{ALTERNATIVES TO THE PROPOSED PROJECT}

\subsubsection{LABORATORY TESTS}

1. One alternative for accomplishing test objectives would to perform laboratory scale test on the reaction of hydrazine fuels with chemical species present in the upper atmosphere.

Admittedly, it is virtually impossible to simulate in the laboratory the phenomena which will be tested by this release.

2. Such tests have been conducted and provide some background relative to the potential reaction of hydrazine fuels in the troposphere. These are discussed in certain documents which describe previous on ground experiments and results and thereby are part of the basis for the proposed hydrazine release experiment (Pitts and other 1980, Tuazon and others 1982).

\subsubsection{NO -ACTION ALTERNATIVE}

1. The no-action alternative would be for the Air Force not to conduct an experiment in space As a result, knowledge of the effects the release of hydrazine fuels would not change relative to the type of information which would be gained from the proposed experiment. 


\subsection{EXISTING ENVIRONMENT}

\subsection{INTRODUCTION}

For purpose of this Environment Assessment, the existing environment will consists of: two parts: (1) the shuttle launch site and atmospheric environment on earth, and (2) the hydrazine travel release, and detonation locations in space.The proposed launch site, Kennedy Spac Center (KSC), is mentioned briefly below. It is discussed in detail in the Shuttle EIS (NASA 1978).

\subsection{EARTH ENVIRONMENT}

\subsubsection{KENNEDY SPACE CENTER LAUNCH SITE}

The Kennedy Space Center (KSC) is located on about 57,000 hectares (140.000 acres) of Merritt Island, Florida, along the Gulf-Atlantic coastal flats. Military installations south of KSC are the adjacent Cape Canaveral Air Force Station, Cape Canaveral and Patrick Air Force Base. KSC is approximately $50 \mathrm{~km}$ due west of Orlando, Florida.

\subsubsection{EARTH ATMOSPHERE}

1. The atmosphere around the surface of the earth is called the troposphere. It extends from the surface of the planet to an altitude of about 10 to $15 \mathrm{~km}$ and is characterized by decreasing temperature and with increasing altitude (see Figure 2.1).

2. There is ongoing concern in the scientific community regarding the production of ozone (primarily due to the consequences of fossil fuel combustion) and the subsequent effect on the troposphere and its ability to shield the plant from ultraviolet radiation. The relationship of the proposed project to this issue is discussed in Section 3.2, Air Quality .

\subsection{SPACE ENVIRONMENT}

\subsubsection{THERMOSPHERE}

1. It is planned that the hydrazine travel release, and detonation will occur in the thermosphere, an area extending outward from about $85 \mathrm{~km}$ above the surface of the earth ( see Figure 2.2). This region of "outer space " is characterized by increasing temperature and pressure with altitude. 


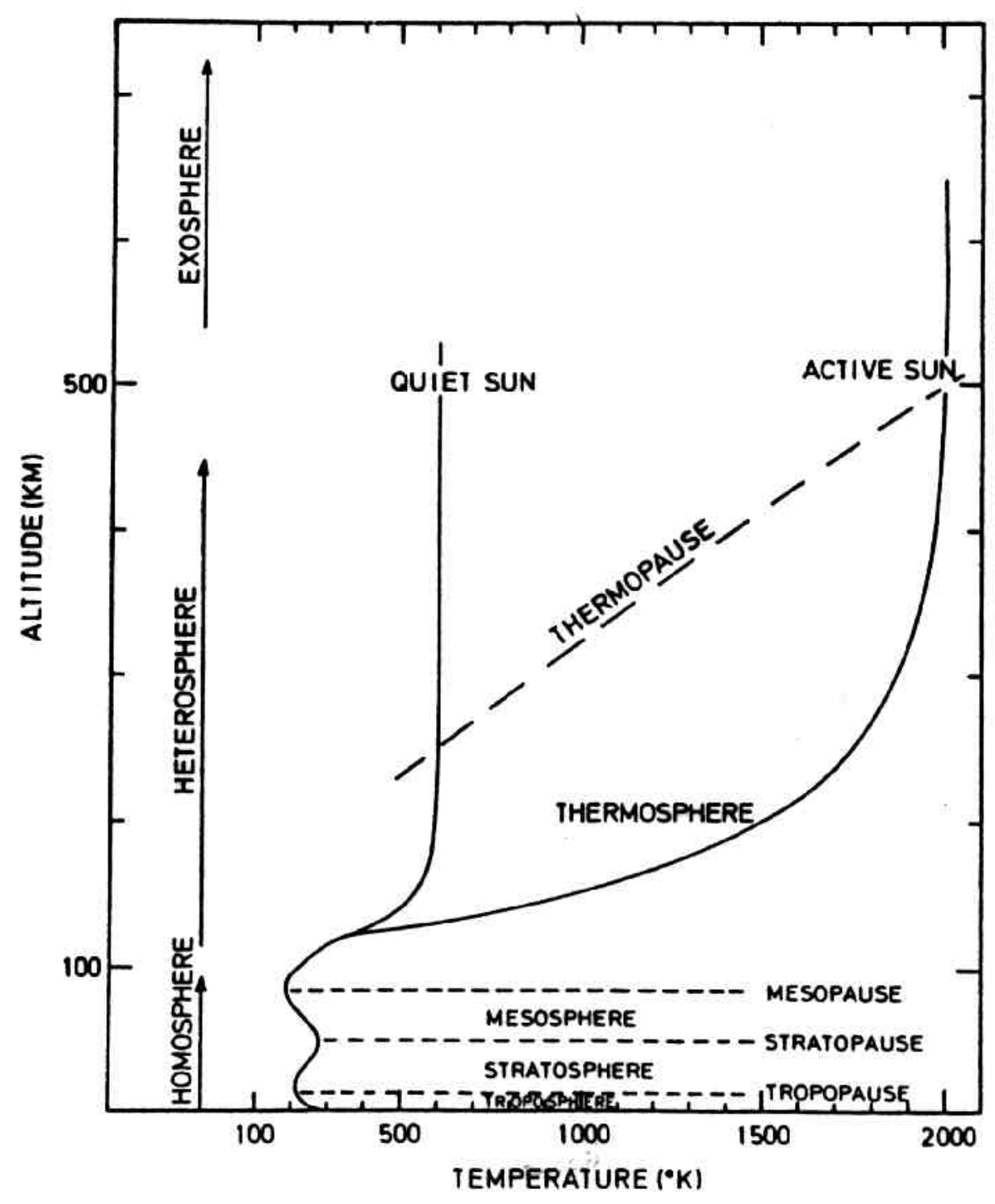

FIGURE 2.1

VERTICAL DISTRIBUTION OF TEMPERATURE

IN ATMOSPHERIC REGIONS HYDRAZINE RELEASE EXPERIMENT 


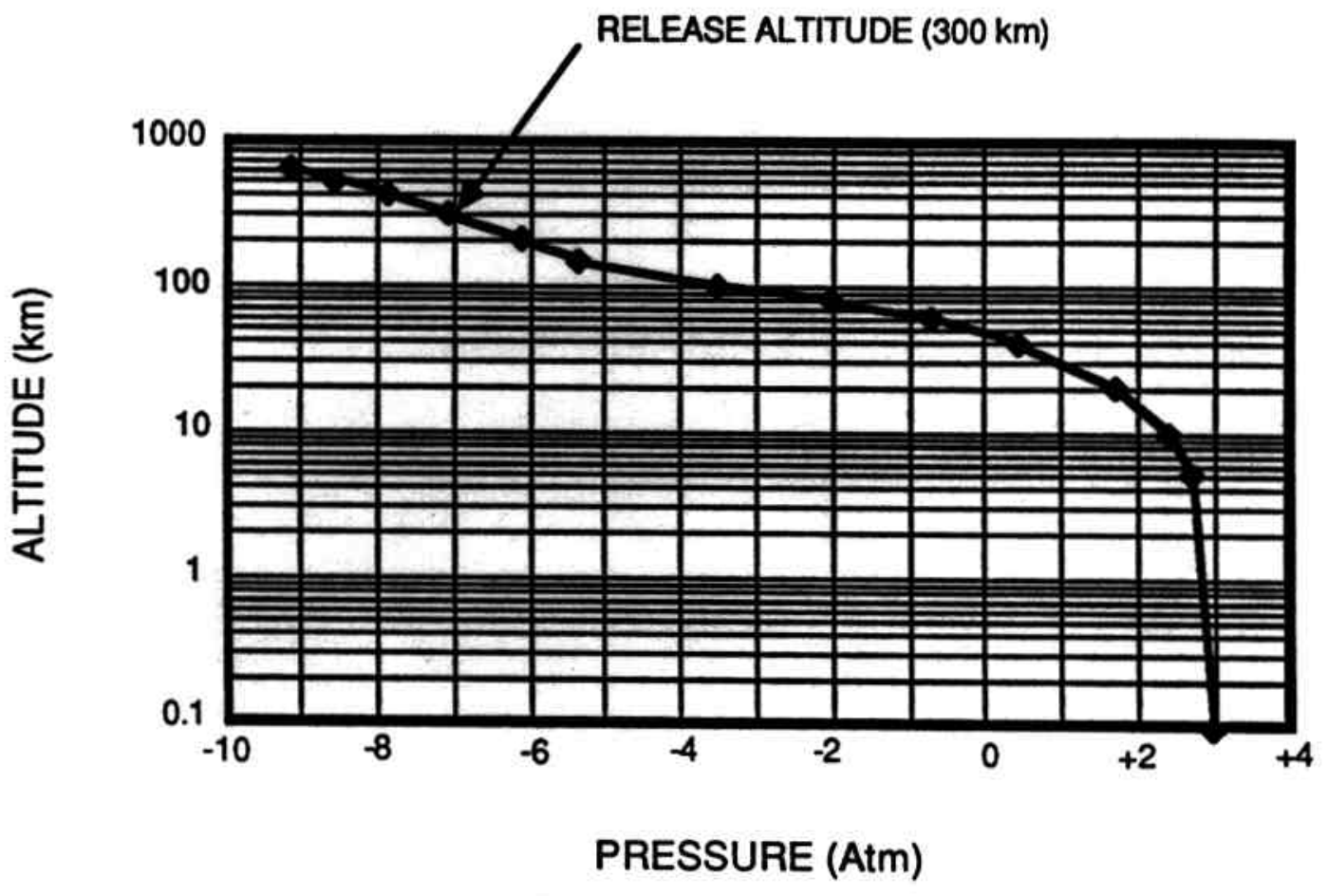

FIGURE 2.2

ATMOSPHERIC PRESSURE WITH RESPECT TO ALTITUDE HYDRAZINE RELEASE EXPERIMENT ENVIRONMENTAL SOLUTIONS, INC. 
2. The movement of substances through this area of virtually zero occurs primarily by means of diffusion and advection. Diffusion occurs as molecules moves through space as a result of intramolecular forces. Advection involves the transport of vapors particulates by means of moving air masses. However, beginning at an earth altitude a just above $300 \mathrm{~km}$, advection would be primarily horizontal, as the temperature becomes positive to zero (constant ) at this altitude, there by resisting the vertical motion of air masses.

\subsubsection{MESOSPHERE}

The mesosphere lies below thermosphere, at an altitude of about 50 to $85 \mathrm{~km}$. It characterized by decreasing temperature and pressure with altitude.

\subsubsection{STRATOSPHERE}

The stratosphere is the atmospheric layer which lies below the mesosphere and above the troposphere. The stratosphere is characterized by increasing temperature and pressure with altitude. It is similar to the thermosphere and is, essentially, a near vacuum. 


\subsection{ENVIRONMENTAL IMPACTS OF THE PROPOSED ACTION}

\subsection{INTRODUCTION}

1. The potential effects of the proposed project center on: (1.) the consequences of a successful experiment and the resultant affect effects engendered by the release of hydrazine into the upper atmosphere and potential subsequent on-ground effects; and (2) potential accidents, which could occur on the ground during launch, or in space, thereby releasing hydrazine into the ambient lower, mid upper atmosphere.

2. Most of the effects discussed will be atmospheric or air quality impacts. Others involve surface water and human safety.

3. Many of the potential impacts, largely associated with accidents involving the space shuttle,are addressed in the Shuttle EIS and addressed and incorporated herein by reference.

\subsection{AIR QUALITY}

\subsubsection{CONSEQUENCES OF EXPERIMENT}

\subsubsection{Expected Results}

1. The release of hydrazine fuels is expected to alter the chemical and ionic composition of the upper atmosphere in the vicinity of the release. It will increase the emission of electromagnetic radiation from this localized region of space, so that the emission of ultraviolet, visible, and infrared light will increase. The potential detection of these increase emissions will form the basis of measurements taken during the experiment.

2. The increased electromagnetic radiation would be a transient effect expected to persist for approximately one minute. The enchanced emission in intensities would be sufficiently weak that sensitive telescopes would normally be required for their scientific detection. However, there is the possibility that the increased emission intensity would be visible to the unaided eye, assuming optimum location of the observer.

\subsubsection{Hydrazine Transport}

1. The hydrazine fuels which will be utilized in the experiment are expected to react with chemical 
species present in the atmosphere of the release (thermosphere) is such manner that none of the hydrazine would reach the troposphere. However, the possibility of hydrazine reaching the troposphere of was considered, relative to available mechanisms for and transport and their consequences. In general, the two likely mechanisms for the transport of hydrazine to the troposphere are advection and molecular diffusion.

2. Due to the relative vertical stability of the atmospheric layers from the thermosphere to the lower stratosphere, there would be little, if any, vertical motion of air masses. Therefore, there would be little opportunity for the advection of hydrazine down to the troposphere.

3. The second mechanism available for the transport of hydrazine in space (above100 km) is molecular diffusions, whereby hydrazine molecules move through the atmosphere as a result of intramolecular forces. A brief analysis of hydrazine transport by molecular diffusion appears in Appendix A (to be presented in Final EA). Based on this analysis, and assuming an initial concentration of $45.4 \mathrm{~kg} / \mathrm{m}^{3}$ for the release, the concentration after approximately 50 years wouldbe $4.5 \times 10^{-6} \mathrm{ug} / \mathrm{m}^{3}$ at altitude of $100 \mathrm{~km}$, several orders, of magnitude below the exposure limit of $0.04 \mathrm{mg}^{3}$ (NIOSH). However, the diffusion time is so long that it is highly unlikely that any hydrazine would ever reach an altitude as low as $100 \mathrm{~km}$, as it dissociates rapidly under intense electromagnetic radiation and reacts with atmospheric constituents. Further, the concentration in the troposphere would be orders of magnitude less than at an altitude $100 \mathrm{~km}$.

\subsubsection{Hydrazine Reaction Products}

\section{$\underline{\text { Atmospheric Components }}$}

1. As discussed above, hydrazine and other large molecules cannot survive long in the upper atmosphere because of the intensity of ultraviolet radiation and electrons and irons which dissociate the large molecules into simpler molecules. Hydrazine, for example, would be dissociated into the simpler $\mathrm{H}_{2} 0, \mathrm{CO}_{2}, \mathrm{CO}, \mathrm{N}_{2}$ and perhaps $\mathrm{NO}$ or $\mathrm{NO}_{2}$ before reaching the ground.

2. Most of the products of the hydrazine reactions, $\mathrm{H}_{2} \mathrm{O}, \mathrm{N}_{2}, \mathrm{CO}_{2}$ are standard atmospheric components and will produce no significant environmental impact. However, $\mathrm{NO}_{\mathrm{x}}$, which consists of $\mathrm{NO}$ and $\mathrm{NO}_{2}$, does potentially pose an impact through reaction with ozone in the stratosphere whereby the $\mathrm{No}_{x}$ is not consumed. However, the quantity of $\mathrm{No}_{x}$ produced will be insignificant. Consequently, the effects of these hydrazine reaction products will be negligible, regardless of whether they are transported to the troposphere. 


\section{Nitrosamines}

1. The reaction of hydrazine with ozone can potentially produce nitrosamine which are known carcinogens. However, their formation is plausible only if the hydrazine is release close to the earth's surface and in the vicinity of a smoggy city. Further, even if all 200 pounds of hydrazine were to be converted to nitrosamines and reach the surface, it would be diluted by the atmosphere to the extent that its concentration would be insignificant (Molina 1986).

2. Studies addressing the "Atmospheric Reaction Mechanisms of Amine Fuels" (Tuazon1982) have considered the oxidation products dimethylnitramine and N-nitrosdimethylamine. It was found that both compounds react with $\mathrm{OH}$ radicals and the $\mathrm{OH}$ radical reaction represents the major atmospheric reaction pathway for the consumption of dimethylnitramie. Reaction rates showed tropospheric half-lives of approximately two days.

3. Daytime photolysis was found to be the primary degradation process for N-nitrosodimethylamine in these studies. Photolysis reaction rates were found to be three orders of magnitude faster than rate of reaction with $\mathrm{OH}$ radicals.

4. Because the predominant chemical composition of the thermosphere where the hydrazine release would occur is $\mathrm{N}_{2}$ and $\mathrm{O}$, the hydrazine may react in the upper atmosophere with atomic oxygen to produce nitrosamines (minor reaction channel). If such occurs, the futher destruction of nitrosamines (e.g dimethylnitramine) will occur due to reaction with atomic oxygen. Assuming diffusion times similar to those determined for hydrazine, the dimethylnitramine could remain in the upper atmosphere for some time before being consumed in $\mathrm{OH}$ radical reactions. 
5. If the hydrazine does not react significantly with the oxygen atoms in the upper atmosphere, it will react with ozone in the stratosphere after there has been sufficient time to diffuse downward. In this case, the nitrosamines produced by the ozone reactions would be rapidly consumed by $\mathrm{OH}$ radical reactions the stratosphere (half-lives on the order of approximately two days).

6. Regardless of which mechanism occurs, any dimenthylnitramine produced by ozone reactions with hydrazine will be consumed before reaching the troposphere.

\section{$\underline{\text { Conclusion }}$}

1. Hydrazine reaction products could be transported to the troposphere both by diffusion and advection processes. However, as products moves to lower altitudes, their concentrations not only become more dilute, but there are increased opportunities for atmospheric chemical reactions with the unreacted hydrazine.

2. Therefore, the probability of unsafe levels of hydrazine reaction products occurring in the troposphere is considered negligible.

\subsubsection{Ultraviolet Radiation}

1. One result hydrazine reactions with ozone could be a short duration, localized increase in ultraviolet radiation reaching the earth. However, this would require diffusion of hydrazine down to the stratosphere where the perponderance of atmospheric ozone exisits. The increased ultraviolet radiation would be a result of the locally decreased ozone concentration which shields the lower atomosphere from ultraviole radiation.

2. Conceptually, increased radiation could affect either animals populations or other aspects of the earth's environment. While it is expected that most of hydrazine will react under intense radiation in the upper atmosphere, the following discussion assumes that all the hydrazine reacts with ozone. This assumption provides a method for obtaining an upper bound, worst-case estimate of the potential effect of increased ultraviolet radiation. 
3. According to Parker (1980), the theoretical effect releasing $2 \times 10^{9}$ kilograms of $\mathrm{NO}_{\mathrm{x}}$ into the atmosphere at an altitude of 17 kilometers would result in $3 \%$ decrease in stratospheric ozone. This would lead to a $6 \%$ increase in ultraviolet radiation because of reactions with $\mathrm{No}_{\mathrm{x}}$ and ozone. Tuazon (1982) states that the stoichiometry for ozone-hydrazine reactions is about 3.2. Thus, there would be 100 pounds of hydrazine reacting with 150 pounds of ozone if all the hydrazine reacted with ozone. If the stoichiometry of $\mathrm{NO}_{\mathrm{x}}$-Ozone is assumed to be 1:1, the decreased ozone from the reaction would be:

$$
\mathrm{d}=150 /\left(2.2 \times 210^{9}\right) \times 03=10.2 \times 10-^{8}=1 \times 10-^{5} \text { percent }
$$

as an upper bound per container. For two experiments per years, this would result in a $4 \times 10-^{5}$ percent increase in ultraviolet radiation. This amount is considered to be in significant. Similarly, it would be significant if 200 pounds of of hydrazine were involved.

4. The amount of hydrazine to be released is so trivial compared to the amount of any trace species that play some role in ozone depletion that it cannot realistically be quantified.

5. In addition, there is virtually no possibility of producing an "ozone hole" through a point source release. The horizontal wind speeds are sufficiently than the vertical ones that dilution would prevent local effect occurring (Molina 1986).

\subsubsection{CONSEQUENCE OF POTENTIAL ACCIDENTS}

\subsubsection{On-Ground Accident}

1. The overall potential environmental impacts of on-going accident associated with the Shuttle launch and landing were addressed in the Shuttle EIS (NASA 1978). The addition of the GAS containers for the hydrazine release experiment would not create additional impact relative to on-ground accidents.

2. There is the potential for an accidents to occur during onsite handling an transportation of the canisters. The potential impacts associated with such an accident would be due to a worst-case release of 200 pounds of hydrazine into the atomosphere. The likehood of such an occurrence was addressed in the Shuttle EIS (NASA1978) and was determined to be negligible. 
3. The canisters could fail as a result of a larger explosion. In the event of pad explosion unrelated to the proposed project, the effects of the additional 200 pounds of hydrazine would be negligible.

\subsubsection{Liftoff Accidents}

1. The principal potential accident during liftoff is an explosion induced by malfunction in the Shuttle launch vehicle. If such an explosion ocurred, explosive force and temperatures could be expected to result in failure of the hydrazine canisters and ignition of hydrazine.

2. Burning of hydrazine would produce combustion products which have been studied in conjunction with other launch vehicles and rockets. Monomethyl hydrazine and aerozine-50, two of the hydrazine fuels to be used in the experiment, are used by the OMS and attitude control thrusters of the orbiter and the Titan launch vehicle, respectively.

3. Exhaust produce from these fuels have been shown to have no significant effect on air quality.

\subsubsection{Accidents in Space}

1. Shuttle orbiting accidents are considered in the Shuttle EIS. The addition of the two hydrazine GAS containers to the orbiter will not significantly alter either the probability or the consequences of any Shuttle orbiting accidents.

2. Although there is a virtual zero probability of spontaneous canister failure resulting in a leak or explosion in the orbiter bay, it is mentioned here for completeness. A hydrazine leak in the orbiting spacecraft would be contained in the orbiter bay.

3. More likely is the potential for GAS container orbiting accidents following ejection of the GAS container from the Shuttle. These addressed below.

\section{Explosion}

1. Should a container explode prior to the conducts of the experiment, the effect would be to release exhaust products of hydrazine combustion into the upper atmosphere. This would be 
essentially the same as releasing products from hydrazine-fueled rocket firing such as the orbiter attitude control thrusters and would not introduce any new environmental impact. Also, the quantity of would be smaller than is used in the orbiter attitude control thrusters.

2. One possible accident would be the explosion of the GAS container after the placement in low earth orbit but before the command for ordnance detonation, Such explosion could be the result of an ordnance malfunction igniting the hydrazine in some manner.

\section{$\underline{\text { Improper Orbital Placement }}$}

1. In general, the primary errors in orbit placement the could be potentially significant are failure to place the container in an appropriate orbit so that it eventually: (1) falls back to earth or (2) leaves the gravitational field of the earth.

2. In the event the GAS container fails to achieve a stable earth orbit, it will eventually fall back to earth . As it moves to lower altitudes, air resistance heating will increase, with the most probable consequence that the container and enclosed hydrazine would be vaporized. The hydrazine combustion products would be the same as the Shuttle attitude control thrusters and would not pose any new or significant environmental impact.

3. In the event a GAS container fails to achieve earth orbit and leaves the gravitational system of the earth, there would be no impact to air quality.

\section{$\underline{\text { Loss of Ordnance Control }}$}

1. There could be a GAS container obiting accident associcated with the loss of ordnance control Two events are considered possible within this scenario: (1) inability to detonate the ordnance due to failure of some part of the communication system, or (2) detonation of the ordnance under incorrect experimental conditions relative to location.

2. In the event or a communications system or detonator malfuction such that the ordnance cannot be detonated, the GAS container either would remain in orbit or eventually fall back to earth. Assuming that a stable orbit is obtained, the time for the latter event would be quite long, and air quite impacts would be essentially the same as those associated with a sub-orbital trajectory. 
3. However, there might be possibility of retrieving the container, potentially on subsequent Shuttle missions. If the container were eventually retrieved, there would be no environmental impact associated with the loss of ordnance control.

4. A malfunction in the ordnance control system could result in the container being detonated at the incorrect location. In such an event,the experience would fail to accomplish its objectives, because the observation aircraft would not be at the proper location. However, the potential impacts would be the same as those for the experiment functioning as planned.

\subsection{HUMAN POPULATIONS}

\subsubsection{ULTRAVIOLET RADIATION}

1. Ultraviolet radiation is known to be hazardous to human populations. While no quantitative relationship has been documented between ultraviolet radiation doses and occurrences of skin cancer, the link has been established qualitatively. Most research dealing with the effects of increased ultraviolet radiation resulting from decreased ozone in the stratosphere has focused on long-term effects of decreased ozone with the accompanying continuous increase in ultraviolet radiation reaching the earth.

2. In view of the relatively small quantity of ozone which could be depleted as a result of the proposed project, even if all of the hydrazine reacted with ozone, the quantitative increase in ultraviolet radiation would be insignificant.

3. In addition to the expected increase in ultraviolet radiation being insignificant, the release area for the experiment would be over the ocean. Therefore, no population centers would be in the localized area.

\subsubsection{ON-GROUND ACCIDENTS}

1. The overall potential environment impacts of ground accidents associated with the Shuttle launch and landing were addressed in the Shuttle ELS (NASA 1978). The addition of the GAS container for the hydrazine release experiment would create no additional potential for environmental impacts relative to on-ground accidents which could affect personnel at the launch site. 
2. Empty canisters will be shipped to Goddard Space Flight Center for installation in the GAS containers. Consequently, offsite, public transportation accidents pose no potential enviromental impacts.

3. Although negligible, there is the potential for an accident to occur to the loaded canisters during onsite handling and transportation.Shouldthere be a spill at the at the launch site, there would be no significant hazard beyond the site boundaries, Within the site boundaries , the spill would be contained disposed of in an environmental ly acceptable manner: by incineration, neutralization, or controlled dilution and release (NASA 1978).

\subsection{SURFACE WATER EFFECTS}

1. The occurrence of a transportation accident could result in the subsequent release of 200 pounds of hydrazine to the ground and /or surface drainages. Administrative and emergency procedures would dictate containment and sorption of spilled hydrazine. The potential effects of the hydrazine migrating to local drainages would result in the lowering of $\mathrm{pH}$ of the water.

2. Although unlikely, the hydrazine GAS containers might survive a liftoff explosion. There would then be a possibility of localized ocean contamination with hydrazine due to container failure subsequent to falling into the ocean or later, by corrosion.

3. Simplified spill models are available for assessing concentration levels of chemicals spilled into stream at various distances from the spill as a function of the weight of chemical spilled in tons. The Air Force Assessment Model (SAM) was utilized for purposes of this report . While the calculation procedures provided are for streams, rather than ocearns, use of the models provides conservative results for ocean concentrations.

4. Appendix B presents a brief description of the calculations performed, assuming that 100 pounds of hydrazine spills into the ocean in the unlikely event that a canister survives a liftoff explosion. Results of the calculations yield a concentration of $20 \mathrm{ppm}$ a distance of 0.1 mile from the spill point for each of the two containers planned for the experiment. Comparing this value to a toxicity level of $146 \mathrm{ppm}$ for rainbow trout in fresh water (given in the SAM model), the toxicity effect of a canister failure in the ocean is expected to be highly localized at the failure point. Mixing and currents will dilute the hydrazine rapidly, as demonstrated by the conservative calculations. 
5. If the two containers should fail at precisely the same location, the concentration would be doubled, or $40 \mathrm{ppm}$, at a distance of 0.1 mile from the failure location. This is still well below the toxicity level of $146 \mathrm{ppm}$ and would have only a highly localized effect.

\subsection{NATURAL ECOLOGY}

1. Increased ultraviolet radiation also can potentially harm other elements of the environment . Specifically, it is known that ultraviolet radiation is harmful to phytoplankton which live in upper, sunlit areas of the oceans (Cloud and Gibor 1980)

2. While specific quantitative relationship are unavailable, the anticipated minute increase in ultraviolet radiation as a result of the proposed project would not be expected to have any significant effect on phytoplankton in the localized area of the release.

3. The amount of hydrazine to be released is so trivial compared to the amount of any trace species that play some role in ozone depletion that it cannot realistically be quantified. In addition, there is virtually no possibility of producing an "ozone hole" through a point source release. The horizontal wind speeds are sufficiently greater than the vertical ones, so dilution would prevent local effects (Molina 1986).

\subsection{NOISE}

1. Noise impacts relative to proposed project would occur only during launch preparation and activation. Noise associated with ejection of the GAS canisters and detonation of hydrazine would not be discernible, either in space or earth

2. In the event of a Shuttle accident, noise impacts would be the same as addressed in the Shuttle EIS documents (AF 1978, NASA 1978). The involvement of the hydrazine-loaded canisters would not be significant.

\section{7 $\underline{\text { SUMMARY OF IMPACTS }}$}

1. The amounts of hydrazine to be used in the chemical release experiments are in insufficient to cause significant environmental impacts from either the successful performance of the test as planned or from postulated, low-probability accidents. 
2. Diffusion times for hydrazines to reach the troposphere are very long and allow more than sufficient time for the hydrazine reactions to occur before the hydrazine reaches the troposphere.

3. Hydrazine reactions with ozone will deplete a negligible amount of ozone temporarily, and the effect of ozone depletion on increased ultraviolet will be negligible. The insignificant levels of potential increase in ultraviolet radiation pose a negligible environmental impact on both human populations and biota.

4. The experiments will have negligible impact on the amount of $\mathrm{No}_{\mathrm{x}}$ in the atmosphere.There would be no worsening of any long-term threat to stratospheric or tropospheric ozone as a result of the experiment. 


\subsection{ALTERNATIVES TO THE PROPOSED PROJECT}

\subsection{LABORATORY TEST ALTERNATIVE}

1. The order to perform laboratory scale tests comparable to the proposed experiment, there would have to be duplication of: (1) upper atmospsheric conditions of temperature, pressure, electromagnetic radiation, and chemical structure, and (2) the diffusion of hydrazine and reaction products in the atmosphere.

2. In the upper atmosphere, there is nearly zero pressure, and temperatures are on the order of 1,000 degrees Kelvin (1,300-1,400 F) (see Figure 2.1). Electromagnetic radiation in the upper atomosphere, particularly the ultraviolet wavelengths, is orders of magnitude stronger than in the troposphere, due to the shielding effect of the ozone in the stratosphere. It is difficult to replicate these upper atmospheric condition of pressure, temperature, and radiation in the laboratory.

3. Chemical composition in the upper atmosphere is predominaintly molecular nitrogen $\left(\mathrm{N}_{2}\right)$ and atomic oxygen $(\mathrm{O})$, due to the strong radiation which causes molecules to dissociate . However, the precise chemical condition has not been completely determined. Therefore, laboratory duplication would be difficult.

4. Other difficulties in achieving upper atmospheric conditions in the laboratory relate to absence of walls, a complex, highly reactive, and ionized chemical environment, and transport of the reaction products over distances which are great compared to those in a laboratory apparatus.

\subsection{NO-ACTION ALTERNATIVE}

1. Under the No-Action Alternative, the proposed would experiment would not be conducted .

2. Implementation of No-Action Alternative would mean that mission objectives would not be accomplished. This would deny to the Air Force the opportunity to assess the environmental consequences of an accidental hydrazine release in space andto develop any mitigating measures deemed desirable. 


\subsection{SUMMARY}

1. The experiment represents the best alternative accomplishing mission objective of increasing the knowledge base on environment effect of hydrazine fuels.

2. The deficiencies and problems associated with laboratory testing are such that it does not represent a viable alternative to the full-scale test in space. Because of this, laboratory testing would not accomplish mission objectives.

3. The No-Action Alternative fails to satisfy mission objectives. 


\subsection{UNAVOIDABLE ADVERSE EFFECTS AND MITIGATIONS MEASURES}

1. Should there be any adverse effects from the proposed experiment or attempts to conduct the experiment, they would likely be the result of a malfunction and/or an accident releated to the space shuttle. As proposed, there are no unavoidable adverse effects inherent in the procedures and conduct of the experiment itself.

2. Certain aspects of the proposed experiment are Air Force operational procedures, yet are mitigation measures. There procedures primarily are concerned with the handling, loading, and shipping of the hydrazine canister and with the shuttle launch. These are designed to minimize the chance of an accident occurring and, should one occur, to minimize its extent. These are discussed below:

. The canister will be designed to the requirements of the GAS container dimensions and weight limitations.

- The GAS container ejection mechanism will be designed to minimize the probability of either improper orbital placement or loss of ordnance control.

. The Air Force has developed appropriate safety procedures for the routine handling, transport, and utlization of hydrazine fuels, which are utilized for numerous other operations. These procedures include quarterly personnel qualification/certification training on the handling of spills.

- The safety and other operational requirements of the shuttle will be fulfilled by the contractor selected to design and construct the hardware and provide integration services.

. Provisions will be made for unloading, the canisters in the event of an extended launch delay or other such circumstance. 


\subsection{RELATIONSHIP BETWEEN LOCAL, SHORT-TERM USE OF THE ENVIRONMENT AND THE MAINTENANCE AND ENHANCEMENT OF LONG-TERM PRODUCTIVITY}

1. Analyses of the proposed experiment and associated space launch indicate that the proposed project will not adversely affect long-term productivity of the environment.

2. The primary area where it might be anticipated that adverse effects could occur would be in the degradation of lower or upper atmospheric air quality. However, as discussed in Section 3.2, Air Quality, the project will not create such adverse effects.

3. Therefore, the short-term effects of the project is not anticipated to adversely affect the long-term productivity of the environment.

\subsection{IRREVERSIBLE AND IRRETRIEVABLE COMMITMENT OF RESOURCES THAT WOULD BE INVOLVED IN THE PROPOSED ACTION, SHOULD IT BE IMPLEMENTED}

1. There would be some irreversible and irretrievable commitments of resources involved in implementing the proposed project. These would include the small amount of energy expended in the production of the hydrazine fuels, plus, the energy utilized for its transport to KCS. In addition, materials utilized in the construction of the canisters and GAS satellites would be irretrievable.

2. However, the significant expenditures of materials and energy would be those committed to the Space Shuttle. These were addressed previously in the Space Shuttle EIS (AF 1978, NASA 1978). It was concluded that the long-term,benefits to be derived from increased knowledge gained from activities in space would, in the long-term, justify the necessary commitments of material and human resources. 


\subsection{CONSIDERATIONS THAT OFFSET THE ADVERSE ENVIRONMENTAL EFFECTS}

1. It is anticipated that there would be no adverse environmental effects resulting from the proposed project itself.

2. Potential adverse effects resulting from the attendant space shuttle activities have been addressed in the Shuttle EIS (AF 1978, NASA 1978). The potential, environmental, political, and economic information and benefits to be provided by activities associated with the space shuttle are expected to be significant and positive compared to potential adverse effects of the program. 


\title{
9.0 PERSONS AND ORGANIZATIONS CONTACTED
}

\author{
Mario J. Molina, Ph.D. \\ Senior Research Scientist \\ Jet Propulsion Laboratory \\ California Institute of Technology \\ Pasadena, California 91109 \\ Miro Z. Kenezvic, Ph.D. \\ Environmental Solutions, Inc. \\ Irvine, California 92718 \\ Carolyn Trindle \\ Environmental Solutions \\ Irvine, California 92718 \\ John E. Edwards \\ $\mathrm{SD} / \mathrm{DEV}$ \\ HQ Space Division \\ Los Angeles, California 90009 \\ Don Shaw \\ Environmental Solutions, Inc. \\ Irvine, California 92718
}




\subsection{REFERENCES}

Abramovitz, M.and I.Stegun 1965. Handbook of Mathematical Functions. Dover Publications, New York.

Cloud P. And A. Gibor 1970. “The Oxygen Cycle,” The Biosphere . W.F.Freeman and Company, San Francisco.

Department of the Air Force (AF) 1978. Final Environment Impact Statement, Space Shuttle Program, Vandenberg AFB, California (January).

Department of the Air Force (AF) 1983. Supplement to Final Environmental Impact Statement, Space Shuttle Program, Vandenberg AFB, California (July).

Molina, M Ph.D. 1986. Review of Draft Environmental Assessment, Hydrazine Release Experiment (November).

National Aeronautics and Space Administration (NASA) 1978 . Final Environment Impact Statement, Space Shuttle Program (April). This document the Kennedy Space Center launch site.

Parker, S., Ed. 1980 McGraw-Hill Encyclopedia of Environmental Science. McGraw-HIll Book Company, New York, NY.

Pitts, J. Jr., and others 1980. “Atmospheric Chemistry of Hydrazine: Gas Phase Kinetics and Mechanistic Studies." Engineering and Services Laboratory, Air Force Engineering and Services Laboratory, Air Force Engineering and Service Center, ESL-TR- 80-39, Tyndall Air Force Base, Florida (August ).

Potts, R. And J. Hagopian 1980. "Spill Assessment Model (SAM) Procedure for Manual Field Calculations." Engineering and Services Laboratory , Air Force Engineering and Service Center, ESL-TR-80-22, Tyndall Air Force Base, Florida (April).

Reid, R., J. Prausnitz, and T. Sherwood 1977. The Properties of Glass and Liquids Third, Edition. McGraw-Hill Book Company, New York, NY. 
Skelland, A. 1974. Diffusional Mass Transfer. John Wiley \& Sons, New York.

Tuazon, E and other 1982, “Atmospheric Reaction Mechanisms of Amine Fuels.” Engineering and Services Laboratory, Air Force Engineering and Services Center, ESL-TR-82-17, Tyndall Force Base, Florida (March)

U.S. Department of Health and Human Services 1985. NIOSH Pocket Guide to Chemical Hazards (NIOSH). Public Health Service, U.S Government Printing Office, Washington, D.C. (September). 


\title{
APPENDIX A
}

\section{DIFFUSION OF HYDRAZINE FUELS IN THE UPPER ATMOSPHERE}

\author{
APPENDIX A \\ Diffusion of Hydrazine Fuels \\ in the Upper Atmosphere
}

1. Following its release, the diffusion of hydrazine in the atmosphere is governed by Fick's law of diffusion for bimolecular gases, provided the hydrazine does not: (1) react with any of the components of the air, or (2) break down due to dissociation caused by the intense electromagnetic radiation. To gain an upper bound estimate of the hydrazine concentrations at altitudes below the release point, it can be assumed that no reaction or dissociated will occur. In fact, however, most of the hydrazine will have reached or dissociated before much diffusion can occur. The following analysis estimates a conservative upper bound hydrazine concentration at $100 \mathrm{~km}$ altitude due to a release of $45.4 \mathrm{~kg}$ hydrazine (taken to be the maximum release) at an altitude of $300 \mathrm{~km}$. 


\section{A.1Diffusion Equation}

1. The molecular diffusion will be governed by the spherical diffusion from a point source into an infinite region. If diffusion outward into space is conservatively neglected, the diffusion can be simulated mathematically as diffusion into a semi-infinite space from a region where the concentration is suddenly changed from zero to a value, $\mathrm{C}_{0}$. In this case, the concentration on a function of time, $t$ and distance, $\mathrm{z}$, is given by Skelland (1974) as;

$$
\mathrm{C}(\mathrm{t})=\mathrm{C}_{0} \operatorname{erfc}\left(\mathrm{z}[\mathrm{Dt}]-{ }^{1 / 2} / 2\right)
$$

where $\mathrm{C}_{0}$ is the initial concentration following the release, $\mathrm{D}$ is the molecular diffusivity of hydrazine in air, and $\mathrm{z}$ is the distance from the source, increasing positively downward from the point of release. The function erfc () is the complementary error function, defined as;

$$
\operatorname{erfc}()=1-\operatorname{erf}()
$$

where $\operatorname{erf}()$ is the error function.

2. Figure A.1 shows a plot of the concentration ratio $\mathrm{C}(\mathrm{t}) / \mathrm{C}_{0}$ in terms of parameter $\mathrm{u}$, where:

$$
\mathrm{u}=\mathrm{z} / 2(\mathrm{DT})-{ }^{1 / 2}
$$




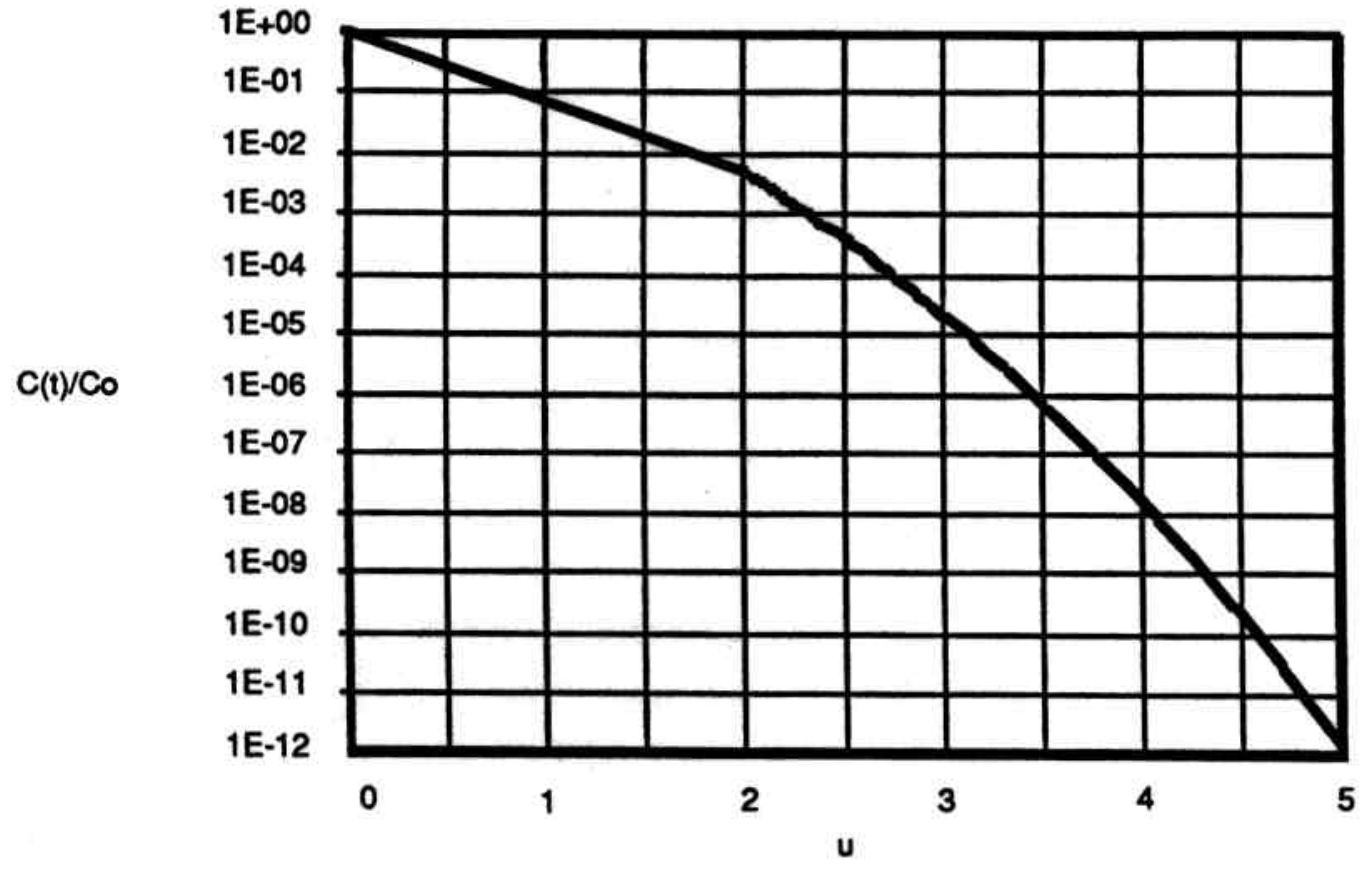

FIGUREA.1

UNSTEADY DIFFUSION CONCENTRATION RATIO

HYDRAZINE RELEASE EXPERIMENT

ENVIRONMENTAL SOLUTIONS, INC. 
The values shown on Figure A.1 were obtained from Table 7.3 of Abramovitz (1965) for the range $u=2$ to $u=5$. For the range from $u=0$ to $u=2$, a straight line was drawn from the value of 1.0 at $u=0$ to the table value at $u=2$.

\section{A.2 Molecular Diffusivity}

1. The molecular diffusivity used in the definition of $\mathrm{u}$ in the above relation was approximated for hydrazine in air from Skellard (1974), using the following equation;

$$
\begin{array}{rl}
\mathrm{D}=0.0018583 \mathrm{~T}^{3 / 2} & \mathrm{SQRT}\left(\left[1 / \mathrm{M}_{\mathrm{A}}\right]+1 /\left[\mathrm{M}_{\mathrm{B}}\right]\right) \\
& \mathrm{P} \times\left(_{\mathrm{AB}}^{\mathrm{S}}\right)^{2} \times \mathrm{W}_{\mathrm{D}, \mathrm{AB}}
\end{array}
$$

where;

$\mathrm{T}$ is temperature in degrees $\mathrm{K}$,

$\mathrm{M}_{\mathrm{A}}$ is the molecular weight of hydrazine $=32.05$,

$\mathrm{M}_{\mathrm{A}}$ is the molecular weight of air=17.7 at $300 \mathrm{~km}$,

$\mathrm{P}$ is the pressure in atmospheres,

$\mathrm{S}_{\mathrm{AB}}$ is the Lennard-Jones force constant in Angstrom units, and

$\mathrm{W}_{\mathrm{D}, \mathrm{AB}}$ is the Collision Integral.

2. Using the 1976 standard atmosphere (National Oceanographic and Atmospheric Administration 1976), the pressures at $100 \mathrm{~km}$ and $300 \mathrm{~km}$ are $3 \times 10-{ }^{7}$ atm and $9 \times 10-{ }^{11}$ atm, respectively. Analysis of the effect of pressure on $\mathrm{C}(\mathrm{t}) / \mathrm{C}_{\mathrm{o}}$ shows that $\mathrm{C}(\mathrm{t}) / \mathrm{C}_{\mathrm{o}}$ increase with increasing pressures. The above equation from Skelland shows that $\mathrm{D}$ decreases with increasing $\mathrm{P}$, and it can be seen from the previous equation relating $u$ to $D$ that $u$ decrease as $D$ decrease. Figure A-1 indicates that $\mathrm{C}(\mathrm{t}) / \mathrm{C}_{\mathrm{o}}$ increase with decreasing $\mathrm{u}$. Therefore, the higher pressure of $3 \mathrm{x}$ $10-^{7}$ atm for an altitude of $100 \mathrm{~km}$ was used in the Skelland equation to estimate molecular diffusivity to yield a conservatively high concentration estimate at $100 \mathrm{~km}$.

3. The collision integral is approximated by the relationship;

$$
\mathrm{W}_{\mathrm{D}, \mathrm{AB}}=\mathrm{kT} / \mathrm{e}_{\mathrm{AB}}
$$


where; $\quad \mathrm{T}$ is the temperature in degrees $\mathrm{K}$, $\mathrm{k}$ is the Bolzmann constant, and

$$
{ }^{\mathrm{e}} \mathrm{AB}=\mathrm{SQRT}\left({ }_{\mathrm{A}}^{\mathrm{e}} \mathrm{x}{ }_{\mathrm{B}}^{\mathrm{e}}\right) .
$$

4. The Lennard-Jones force constant ${ }_{\mathrm{AB}}^{\mathrm{S}}$ is given by;

$$
\left.{ }_{\mathrm{AB}}=\right) 0.5\left({ }_{\mathrm{A}}^{\mathrm{S}}+{ }_{\mathrm{B}}^{\mathrm{S}}\right)
$$

where $\mathrm{S}_{\mathrm{A}}$ and $\mathrm{S}_{\mathrm{B}}$ are approximated for hydrazine and air from the relationship;

$$
\mathrm{s}=(5 / 6) \times \mathrm{V}_{\mathrm{C}}^{1 / 3}
$$

5. For this analysis, the critical volume, $\mathrm{V}_{\mathrm{c}}$, was approximated from the following relationship (Reid and others 1977);

$$
\mathrm{V}_{\mathrm{c}}=40+[\mathrm{v},
$$

where v's are the Lydersen critical volume increments . The units are $\mathrm{cm}^{3} / \mathrm{gram}$ - mole.

6. For air at $300 \mathrm{~km}$, assuming that it is composed of $\mathrm{N}_{2}$ and $\mathrm{O}$, the critical volume is approximated by;

$$
\text { c air }=40+64+20=124 \mathrm{~cm}^{3} / \text { gram }-\mathrm{mole}
$$

and for hydrazine, the critical volume is approximated by;

$$
\mathrm{V}_{\mathrm{ch}}=40+2(28)=96 \mathrm{~cm}_{3} / \text { gram-mole }
$$

7. These values give the following for the Lennard-Jones force constants:

$$
\begin{aligned}
& { }^{\mathrm{s}} \text { air- }(5 / 6) \times(124)^{1 / 3}=4.156 \text { Angstrom units, } \\
& { }^{\mathrm{s}} \mathrm{H}=(5 / 6) \times(96) 1 / 3=3.816 \text { Angstrom units and } \\
& { }^{\mathrm{s}} \text { air/H=0.5(4.156+3.816)= } 3.986 .
\end{aligned}
$$


8. Values of e/k were approximated from Reid and others (1977). From Appendix C,

$$
\mathrm{e} / \mathrm{k})_{\text {air }}=786 \mathrm{~K}
$$

and from the relationship;

$$
(\mathrm{e} / \mathrm{k})=0.75 \mathrm{~T}_{\mathrm{c}}
$$

the value for hydrazine is;

$$
(\mathrm{e} / \mathrm{k})_{\mathrm{H}}=0.75(653)=489.8 \mathrm{~K}
$$

where the critical temperature of $653 \mathrm{~K}$ was obtained from Appendix A (Reid and others 1977). Thus, the value of e/k for the mixture is from above;

$$
\left(\mathrm{e} / \mathrm{k}_{\text {air H}}=\mathrm{SQRT}(78.6 \times 489.8)=196.2 \mathrm{~K} .\right.
$$

9. This yields a value for the collision integral of;

$$
\mathrm{W}_{\mathrm{D}} \text {, air-H-T(e/k) air-H }
$$

which, at an ambient temperature of $976 \mathrm{~K}$ at $300 \mathrm{~km}$ is:

$$
\mathrm{W}_{\mathrm{D}}, \text { air }^{-}{ }_{\mathrm{H}}=976 / 196.2=4.975 \text {. }
$$

10. Substituting the appropriate parameters in the above equation for molecular diffusivity;

$$
\begin{gathered}
\mathrm{D}=1.8583 \times 10-{ }^{3} \times 976^{3 / 2} \times \operatorname{SQRT}(\{1 / 7.7)+(1 / 32.05\})\left(3 \times 10-{ }^{7} \times(3.986)^{2} \times 4.975\right) \\
\mathrm{D}=7.1 \times 10^{5} \mathrm{~cm}^{2} / \mathrm{sec} \\
D=7.1 \times 10-5 \mathrm{~km}^{2} / \mathrm{se} \\
D=0.25 \mathrm{~km}^{2} / \mathrm{hr}
\end{gathered}
$$


11. To obtain a qualitative verification of the above diffusion coeffcient, it can corrected to a pressure of 1 atmosphere. This would yield a value of;

$$
\text { Dlatm }=(7.1 \times 105)(3 \times 10-7)=0.21 \mathrm{~cm} 2 / \mathrm{sec} .
$$

This value compares reasonably well with other air-gas at atmospheric pressure.

For example, Reid and others (1977) report a value of 0.142 for air- $\mathrm{CO}_{2}, 0145$

for air-ethanol, and 0.288 for air-water.

2. The diffusion coefficient can be also be estimated within a factor of two or so by:

$$
\mathrm{D}=\mathrm{c} / 2
$$

where $\mathrm{c}$ is the average thermal speed and is the mean free path in the atmosphere. Taking $\mathrm{c} \sim 6 \times 10^{4} \mathrm{~cm} / \mathrm{sec}$ and a mean free path of $14.2 \mathrm{~cm}$ at an altitude of $100 \mathrm{~km}$ quoted in the 1976 U.S. atmosphere,

$$
\mathrm{D}=4.3 \times 10^{5} \mathrm{~cm}^{2} / \mathrm{sec} \text {. }
$$

The diffusion coefficient estimated by this method corresponds well with the $7.1 \times 10^{5}$ $\mathrm{cm}^{2} / \mathrm{sec}$ at $100 \mathrm{~km}$ estimated above.

\section{A.3 Diffusion Times}

1. Using Figure A.1, the concentration ratio of $1 \times 10-{ }^{6}$ corresponds to a value of $u$ of approximately 3.45 . Using this value for $\mathrm{u}$ with $=0.25 \mathrm{~km}^{2} / \mathrm{hr}$ and $\mathrm{z}=200 \mathrm{~km}$ and solving for the time required for a concentration of $1 \times 10-{ }^{6}$ of the release concentration to reach an altitude of $100 \mathrm{~km}$ :

$$
\mathrm{t}=(200 / 6.9)^{2} / 0.25=3360 \text { hours. }
$$

2. For a concentration ratio of $1 \times 10-12$, the value of $u$ is 5 , and the time required would

$$
\mathrm{t}=(200 / 10) 2 / 0.25=1600 \text { hours }
$$

for a concentration level of $1 \times 10^{12}$ of the release concentration to reach an altitude of $100 \mathrm{~km}$. 
Conservatively assuming an initial volume occupied by the release of 1 cubic meter, the initial concentration would be $45.4 \mathrm{~kg} / \mathrm{m}^{3}$ or $45.4 \times 10^{9} \mathrm{ug} / \mathrm{m}^{3}$ At a concentration ratio of $1 \times 10^{-12}$, the concentration would be $45.4 \times 10-{ }^{3} \mathrm{ug} / \mathrm{m}$ or $0.045 \mathrm{ug} / \mathrm{m}^{3}$, which is below the concentration limit of $0.04 \mathrm{mg} / \mathrm{m} 3$ (NIOSH 1985). Concentrations would be even lower and, therefore, irrelevant in the troposphere $(0 \sim 15 \mathrm{~km})$.

4. The conservatism of this conclusion can be shown by taking the concentration of $0.045 \mathrm{ug} / \mathrm{m}^{3}$ as uniform in a spherical space (radius of $200 \mathrm{~km}$ ) to estimate the total hydrazine release reach to this concentration.

The volume of the sphere would be:

$$
\mathrm{V}=(4 / 3)\left(200 \times 10^{3} \mathrm{~m}\right)=3.35 \times 10^{16} \mathrm{~m}^{3} .
$$

The total hydrazine to establish a uniform concentration of $0.045 \mathrm{ug} / \mathrm{m} 3$ would then be:

$$
\left(0.045 \mathrm{ug} / \mathrm{m}^{3}\right)\left(3 \times 10^{16} \mathrm{~m}^{3}\right)=1.5 \times 10^{15} \mathrm{ug}=1.5 \times 10^{6} \mathrm{~kg} .
$$

The actual maximum amount of hydrazine released will be on the order of $50 \mathrm{~kg}$.

5. In reality, concentrations of $0.045 \mathrm{ug}^{3}$ would never be reached at diffusion distance $200 \mathrm{~km}$. The estimated time to producethis concentration by diffusion is 1600 hours presented above. In fact, the hydrazine reacts away on a much faster time scale. The initial reaction are that destroys the hydrazine, e.g.:

$$
\mathrm{O}+\mathrm{CH}_{3} \mathrm{NHNH}_{2}--->\mathrm{CH}_{3} \mathrm{~N}_{2} \mathrm{H}+\mathrm{H} 2 \mathrm{O}
$$

is very fast, i.e.complete on a time scale of seconds. Kinetics of the subsequent reactions are unknown. However, they should be faster than

$$
\mathrm{O}+\mathrm{CH}_{4}^{--->} \mathrm{CH}_{3}+\mathrm{OH}
$$

which is the slowest known reaction of oxygen atoms with a hydride of carbon or nitrogen. Figure A-2 shows a 1/e reaction time versus altitude for this conservative slowest kinetic limit calculated using the $\mathrm{O}+\mathrm{CH} 4$ kinetic and temperature and pressure the from the 1976 U.S. standard atmosphere. This clearly shows that the hydrazine will react away before diffusing as low as $100 \mathrm{~km}$. 


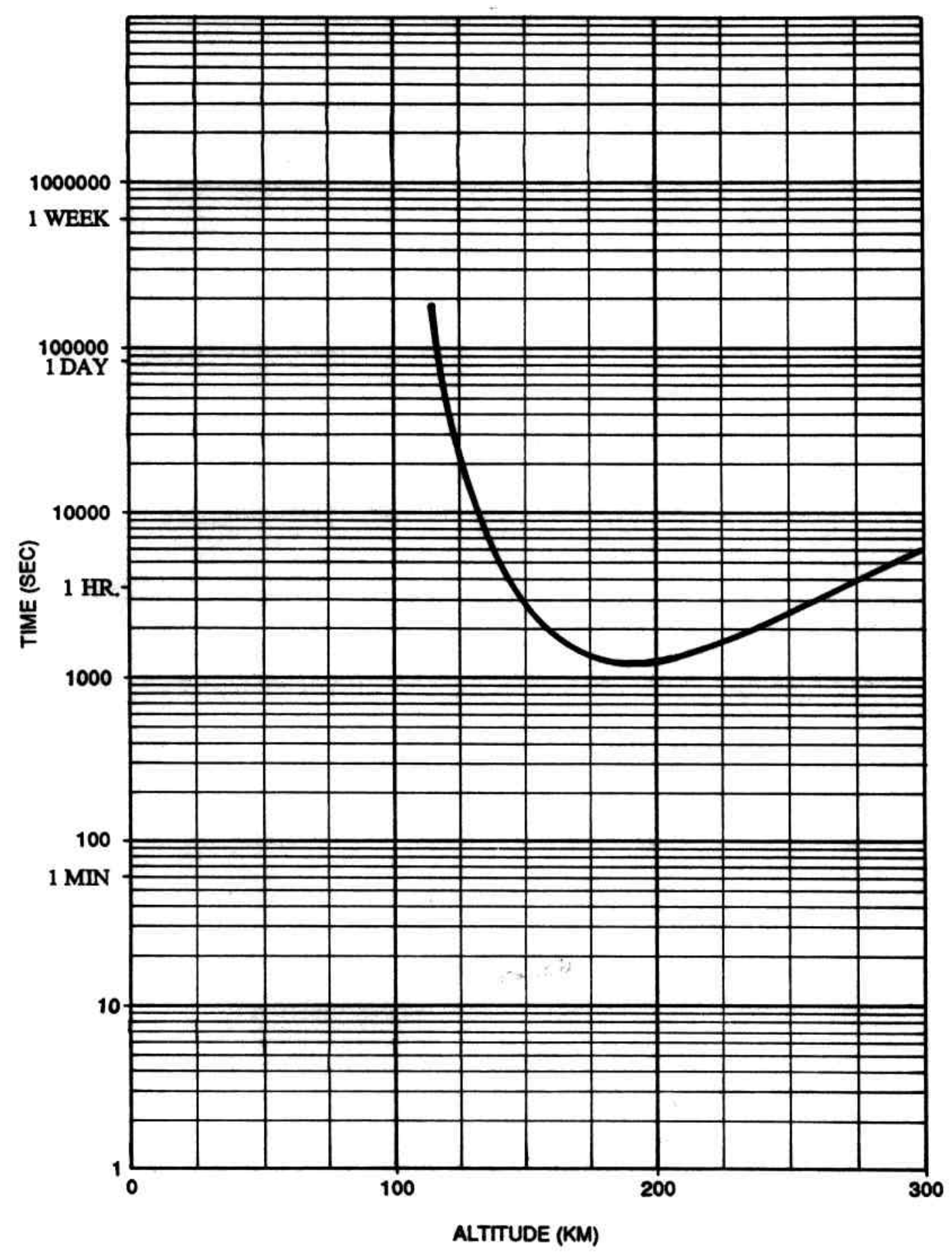

FIGURE A.2

O+CH 4 REACTION TIME WITH RESPECT TO ALTITUDE HYDRAZINE RELEASE EXPERIMENT ENVIRONMENTAL SOLUTIONS, INC. 
APPENDIX B

HYDRAZINE CONCENTRATION IN OCEAN FOLLOWING POTENTIAL LIFTOFF EXPLOSION 


\section{APPENDIX B}

\section{HYDRAZINE CONCENTRATION ON OCEAN FOLLOWING POTENTIAL LIFTOFF EXPLOSION}

1. An approximation of hydrazine concentration in ocean resulting from canister failure consequent to a liftoff explosion can be obtained using the methods of Potts and Hagopian (1980). The methods are based on spills in streams and will predict an upper bound concentration, as depths are shallower in the stream models than in the ocean.

2. Using their spill model for a stream greater than 3.400 feet wide and greater than 200 feet deep, the concentration at a distance 0.1 mile from the point of canister failure is found from Figure A-10 (Potts and Hagopin 1980) to be:

$$
\mathrm{C} / \mathrm{T}=400 \mathrm{mg} / \mathrm{liter} / \mathrm{ton} \text { of spilled hydrazine. }
$$

3. Based on 100 pounds of hydrazine in the canister, the concentration at 0.1 mile from the failure point is given by:

$$
\begin{aligned}
& \mathrm{C}=400 \mathrm{mg} / \text { liter/ton } \times 100 \mathrm{lbs} \times(1 / 2,000) \text { tons } / \mathrm{lb} \text {. } \\
& =20 \mathrm{mg} / \text { liter. } \\
& =20 \mathrm{ppm}
\end{aligned}
$$

At a distance of one mile from the failure point concentration of hydrazine would be:

$$
\begin{aligned}
& \mathrm{C}=10 \mathrm{mg} / \text { liter/ton } \times 100 \mathrm{lbs} \times(1 / 2,000) \text { tons } / \mathrm{lb} .=0.5 \mathrm{mg} / \mathrm{liter} \\
= & 500 \mathrm{mg} / \mathrm{m}^{3} \\
= & 0.5 \mathrm{ppm}
\end{aligned}
$$

4. Based on water toxicity data for hydrazine (Potts and Hagopian), a toxicity level of $146 \mathrm{ppm}$ for a period of one -half hour caused death of rainbow trout in fresh water. Comparing the potential hydrazine level of $20 \mathrm{ppm}$ to the value of $146 \mathrm{ppm}$, it is clear that the concentration resulting from failure of a canister falling into the ocean subsequent to a liftoff explosion is well below the toxicity level at 0.1 mile from the failure point. Consequently, the initial toxic effect of the hydrazine will be highly loclized and short-term, as it will dilute rapidly. 
